This is a final draft post-refereeing version of a paper that has been published in Functional Plant Biology, a CSIRO Publishing journal

The publisher version is available at http://www.publish.csiro.au/paper/FP04018.htm 


\title{
Effects of soil drying and subsequent rewatering on the activity of nitrate reductase in roots and leaves of Helianthus annuus
}

\author{
João Azedo-Silva $^{\mathrm{A}}$, Júlio Osório ${ }^{\mathrm{A}}$, Filomena Fonseca ${ }^{\mathrm{A}}$ and Maria João Correia ${ }^{\mathrm{A}, \mathrm{B}}$ \\ ${ }^{\text {A}}$ Universidade do Algarve, CDCTPV, Campus de Gambelas, 8005-139 Faro, Portugal \\ B Corresponding author; email: jcorreia@ualg.pt
}

\section{Abstract}

The effects of drought on the activity of nitrate reductase (NR) were studied in Helianthus annuus L. plants subjected to soil drying and subsequent rewatering. Drought did not negatively affect the activation state of NR, but resulted in linearly correlated decreases in the activity of the unphosphorilated active form and the total activity of NR, both in roots and leaves. The concentration of nitrate in roots, xylem and leaves also decreased in waterstressed plants, whereas the concentration of total amino acids was only transiently depressed at the leaf level. In contrast, soluble sugars accumulated both in roots and leaves of waterstressed plants. Drought-induced decrease in root NR activity was correlated with the observed changes in root nitrate concentration. A higher percentage of the decrease in foliar NR activity could be explained by the decline in nitrate flux to the leaves than by leaf nitrate content. Following rewatering, the extent of recovery of NR activity was higher in roots than in leaves. The delay in the recovery of foliar NR activity did not result from the persistence of reduced flux of nitrate through the xylem. Several hypotheses to explain the after-effect of soil drying on foliar NR activity are discussed. 


\section{Introduction}

The cytosolic enzyme NADH nitrate reductase (NR; EC 1.6.6.1), the first enzyme in the pathway of nitrate assimilation, is tightly regulated both at the transcriptional (Hoff et al. 1994) and post-translational level (Kaiser et al. 1999). Although the control of gene expression may be an efficient way of regulating the activity of enzymes with a short halflive, such as NR, the activity of this enzyme is also controlled by proteolytic degradation (Galangau et al. 1988), and is subjected to rapid post-translational inactivation through protein phosphorylation and subsequent $\mathrm{Mg}^{2+}$-dependent binding of inhibitory protein (Kaiser et al. 1999; Kaiser and Huber 2001). In all plant species examined so far, NR gene transcription is inducible by nitrate (Hoff et al. 1994; Crawford 1995). In addition to nitrate, both sugars (Klein et al. 2000; Kaiser and Huber 2001), and reduced nitrogen compounds such as amino acids (Hoff et al. 1994; Stitt et al. 2002) have been implicated as internal signals that regulate NR activity.

It has long been recognised that soil drying may cause a decrease in nitrate absorption by the roots and in transport of nitrate from the roots to the leaves, which may lead to foliar nitrate depletion (Shaner and Boyer 1976a; Ferrario-Méry et al. 1998; Foyer et al. 1998). Since NR is a nitrate-inducible enzyme, depletion in foliar nitrate may contribute to explain why the maximal extractable foliar activity of this enzyme has been found to decrease in water-stressed leaves of several species, including maize (Shaner and Boyer 1976a; Foyer et al. 1998; Abd-El Baki et al. 2000), tobacco (Ferrario-Méry et al. 1998), and wheat (Larsson et al. 1989). However, contradictory results exist as to the effects of leaf water deficits on the activation state of NR, which has been found to decrease in some cases (Kaiser and BrendleBehnisch 1991; Brewitz et al. 1996; Foyer et al. 1998), but not in others (Ferrario-Méry et al. 1998; Abd-El Baki et al. 2000). 
Under field conditions, plants are likely to be subjected to recurrent periods of drought and precipitation leading to fluctuating soil water content. Therefore, if we are to understand the influences of drought on nitrogen nutrition, we need information concerning how the plants recover their ability to reduce and assimilate nitrogen following the relief of water deficits. Until now, very few studies have been conducted to address that question. In conditions of relatively short periods of water deprivation (less than one week), full recovery of NR activity was found to occur soon after rehydration of tobacco (Ferrario-Méry et al. 1998) and maize leaves (Foyer et al. 1998). However, the work of Shaner and Boyer (1976a) evidenced that the recovery of NR activity may be delayed when rehydration is not accompanied by the restoration of nitrate flux to leaves. Nitrate flux to the leaves is dependent on transpiration rate, which often recovers slowly following rewatering, due to the aftereffects of drought on stomata (Correia and Pereira 1994). Therefore, a delay in the recovery of leaf NR activity is likely to occur whenever low transpiration rates persist following rewatering.

Rather than being restricted to the leaves, nitrate reduction may also occur in the roots (Stöhr and Mäck 2001; Pajuelo et al. 2002; Scheurwater et al. 2002). However, studies on the effects of water deficits on nitrate reduction at the root level are rare in the literature. In Helianthus annuus plants, Gollan et al. (1992) found that the concentration of nitrate in the xylem sap decreased with soil water content, whereas the concentration of amino acids was slightly increased. These results were interpreted as suggesting that the activity of NR is promoted in droughted roots of sunflower. In accordance, Goupil et al. (1998) found that abscisic acid, which is known to accumulate in dehydrated tissues, stimulated the activity of nitrate reductase in chicory roots. In contrast, Larsson et al. (1989) reported that NR activity in wheat roots was not affected by ABA and declined when roots were dehydrated under osmotic stress. However, in another study (Abd-El Baki et al. 2000) the activity of nitrate 
reductase was not affected when maize roots were subjected to osmotic stress. These contradictory results indicate that further work is needed in order to elucidate the effects of water deficits on the activity of NR in roots.

The present work was undertaken in order to contribute to a better understanding of the effects of soil drying and subsequent rewatering on nitrate reduction. With that purpose, the activity of the unphosphorylated form, the maximal activity and the activation state of nitrate reductase were assayed both in roots and leaves of sunflower plants subjected to a period of soil water deficit and subsequent rewatering. In order to obtain information on changes is parameters that may be involved in the control of NR activity, the concentrations of nitrate, amino acids and soluble sugars were also quantified, both in roots and leaves, and the flux of nitrate in xylem was estimated.

\section{Material and methods}

Plant material and growth conditions

Helianthus annuus L. seeds (cv. Giant) were soaked overnight and allowed to germinate on wet tissue paper, in darkness. They were then placed in $3 \mathrm{~L}$. pots filled with a mixture of unfertilised peat and vermiculite $(1: 1, \mathrm{v} / \mathrm{v})$. The plants (one per pot) were grown in a controlled-environment cabinet (Fitoclima 16.000 EHVP, Aralab, Portugal) under a photoperiod of $12 \mathrm{~h}$, with light provided by incandescent and fluorescent lamps, supplying a photosynthetically active fluence rate (at the top of the plants) of about $750 \mu \mathrm{mol} \mathrm{m} \mathrm{s}^{-1}$. The temperature was $18^{\circ} \mathrm{C}$ (night) $/ 25^{\circ} \mathrm{C}$ (day) and the relative humidity was $70 \%$ (night) $/ 60 \%$ (day). Watering was done using a complete nutrient solution containing (in mol m $\mathrm{m}^{-3}$ ) $9 \mathrm{NO}_{3}^{-}$, 0.6 $\mathrm{NH}_{4}{ }^{+}, 3 \mathrm{~K}^{+}, 0.6 \mathrm{H}_{2} \mathrm{PO}_{4}{ }^{-}, 3 \mathrm{Ca}^{2+}, 1.2 \mathrm{Mg}^{2+}, 1.2 \mathrm{SO}_{4}{ }^{2-}$ and (in mmol m${ }^{-3}$ ) $11 \mathrm{Fe}^{3+}, 5.4 \mathrm{Mn}^{2+}$, $0.48 \mathrm{Zn}^{2+}, 26 \mathrm{H}_{3} \mathrm{BO}_{3}$ and $0.02 \mathrm{Mo}_{7} \mathrm{O}_{24}{ }^{6-}$. Throughout the whole experimental period the plants remained at the vegetative phase of development. 
Water deficit treatment and sampling

From sowing until the beginning of water deficit imposition, all the pots were regularly brought to field capacity (each two days). The onset of water deficit imposition took place 20 days after sowing, when the plants exhibited 4-5 leaves. Water stress was imposed by replacing only partially the water lost by evapotranspiration (determined gravimetrically). To achieve an approximately constant rate of soil drying, the percentage of water lost that was replaced by watering was progressively increased (from $25 \%$ to $75 \%$ ) in order to compensate for the increase in transpiring leaf area. Soil drying lasted for 12 days. During the afternoon of the last day of soil drying the water-stressed pots were rewatered to field capacity. In the case of the plants referred to as well watered, all the water lost by evapotranspiration was replaced by watering throughout the entire experimental period.

Measurements and sampling of leaves, xylem and roots of plants subjected to water deficit took place 5 (short stress), 8 (intermediate stress), and 12 days (prolonged stress) after the onset of soil drying. Rewatered plants were sampled on the 2 days following rewatering. Well-watered plants were sampled the days preceding sampling of water-stressed plants and 3 days following rewatering. Five plants per treatment were harvested at each sampling date. Because there are marked diurnal changes in the transcriptional and post-translational regulation of NR, all the measurements and sampling were done during the $4^{\text {th }}$ hour of the photoperiod, when the activity of cytosolic nitrate reductase from other species has been reported to reach its highest levels both in roots (Stöhr and Mäck 2001) and leaves (Galangau et al. 1988; Geiger et al. 1998; Kandlbinder et al. 2000; Scheible et al. 2000). Two recently expanded leaves per plant were used for measurements and sampling: half of the lamina from the most recently expanded leaf was sampled for NR activity, the rest of the lamina being used to punch leaf discs in which the concentrations of nitrate, amino acids and soluble sugars were determined; the leaf located immediately below was used to determine transpiration rate 
and leaf water potential. Xylem samples were collected from detached shoots, as described below. In the case of the root samples, they represent pooled samples of the entire root system. Leaf, xylem and root samples were quickly frozen in liquid nitrogen, and stored at $80^{\circ} \mathrm{C}$ until analysis.

Measurements of water status, transpiration rate and sampling of xylem sap

Soil water status was regularly assessed by weighing the pots before each watering. Soil fresh mass is expressed as a percentage of the maximum fresh mass at field capacity that was determined before the onset of water deficit imposition. Leaf water status was assessed by measuring leaf water potential $(\Psi)$ using a pressure chamber (PMS Instruments, Corvallis, OR, USA). The transpiration rate of the leaves was determined under the conditions of the growth chamber, using a portable gas exchange measuring system (HCM-1000, H. Walz, Effeltrich, Germany).

Samples of xylem sap were expressed from 200-250 mm long shoot-ends enclosed in a pressure chamber, by applying an overpressure of around $0.4 \mathrm{MPa}$. In order to avoid the contamination by broken cells at the cut surface, the first drop of exudate was discarded, only the exudates subsequently produced $(20-30 \mu \mathrm{L})$ being collected. We are aware that expressing xylem sap from detached shoots, using a pressure bomb, has been criticised (Schurr 1998). Therefore, a preliminary experiment was performed to evaluate the procedure used in this study to collect the samples of xylem sap. Entire shoots of well-watered plants were detached at predawn, recut under water, and transferred to flasks containing the complete nutrient solution either at the concentration above described or diluted to $75 \%$ and $50 \%$ of the initial concentration. After having been kept 60 min in darkness, the shoots were transferred to the growth chamber were they remained 90-150 min after the lights were switched on. At the end of the feeding assay, one sample of each feeding solution was collected and xylem sap was expressed from 4-5 shoot-ends per feeding solution, as described above. As shown in Fig. 1, 
mean nitrate concentrations measured (see below) in the samples of xylem sap were similar to the concentrations in the feeding solutions supplied directly to the transpiring detached shoots. This finding indicates that the concentration of nitrate determined in the sap expressed from detached shoots is similar to the concentration of nitrate being transported in the xylem sap of intact sunflower plants. This is in accordance with other reports (Correia et al. 1999; Borel and Simonneau 2002) that supported the use of the pressurisation technique for collecting xylem sap, provided sap dilution by symplastic water is avoided by collecting only low-volume exudates, as done in the present work.

Extraction and assay of nitrate reductase activity

Frozen samples of leaves and roots were ground to a fine powder in a mortar precooled with liquid nitrogen. NR activity was extracted and assayed as in Long and Oaks (1990), using leupeptin or chymostatin in the extraction buffer to stabilize the enzyme in leaves and roots, respectively. The crude homogenate was centrifuged for $20 \mathrm{~min}$ at 5000 r.p.m. and $4^{\circ} \mathrm{C}$, the NR activity in the supernatant being assayed immediately. NR activity was measured either in the presence of $5 \mathrm{mM}$ EDTA or $10 \mathrm{mM}$ magnesium acetate (final concentrations in the respective assays). The activation state of NR was determined as the activity determined in the presence of $\mathrm{Mg}^{2+}$, which usually reflects the activity of the unphosphorylated active form $\left(\mathrm{NR}_{\mathrm{act}}\right)$, divided by the maximal $\mathrm{NR}$ activity measured in the presence of $5 \mathrm{mM}$ EDTA ( $\mathrm{NR}_{\max }$ ), and is expressed as a percentage (MacKintosh et al. 1995; Ferrario-Méry et al. 1998).

Quantification of nitrate, amino acids and soluble sugars

Nitrate and amino acids were extracted, from intact leaf discs and powdered root samples, with $50 \%(\mathrm{v} / \mathrm{v})$ ethanol, at $80^{\circ} \mathrm{C}$, during $10 \mathrm{~min}$. Nitrate was quantified with a nitrite/nitrate colorimetric assay (Roche Diagnostics, Mannheim, Germany) modified to be used in 96 well plates. In short, xylem samples and extracts from roots and leaves were 
diluted to a final volume of $100 \mu \mathrm{L}$ and incubated for $30 \mathrm{~min}$, at room temperature, in $50 \mu \mathrm{L}$ of potassium phosphate buffer containing $8 \mu \mathrm{g}$ NADPH and $0.02 \mathrm{U}$ nitrate reductase. The amount of nitrite formed was measured at $540 \mathrm{~nm}$ after the addition of $50 \mu \mathrm{L}$ sulphanilamide and $50 \mu \mathrm{L}$ N-(1-naphthyl)-ethylenediamine dihydrochloride. For each plate, two standard calibrations were made using potassium nitrate (0.1-8.0 pmol per well). When nitrate reductase was excluded from the assay, no reaction was detected, indicating that the amounts of nitrite on the samples were negligible. Total amino acids (except proline) were quantified by the ninhidrin method, modified in order to eliminate interference resulting from the presence of sugars in the extracts (Magné and Larher 1992).

Soluble sugars were extracted, from intact leaf discs and powdered root samples, with $80 \%$ (v/v) ethanol, at $80^{\circ} \mathrm{C}$, for $20 \mathrm{~min}$. Soluble sugars were quantified using a spectrophotometric enzyme-coupled assay (Jones et al. 1977). In short, glucose, fructose and sucrose were determined, in a reaction mixture coupled to the reduction of $\mathrm{NADP}^{+}$, recording the absorbance changes at $340 \mathrm{~nm}$, after the sequential addition of glucose-6-phosphate dehydrogenase, phosphoglucose isomerase and invertase respectively.

\section{Data analysis}

Statistical analysis and graphic display were performed with SPSS (Release 11.5.0, SPSS Inc., Chicago, IL, USA) and SigmaPlot (Version 8.02, SPSS Inc., Chicago, IL, USA) software packages, respectively. At each point of the soil drying cycle and subsequent recoveries, the statistical significance of differences between the water stress treatment and the corresponding control were tested by an independent-samples Student's t-test. Relationships between observed variables were described and tested for significance using simple linear and multiple regression techniques.

\section{Results}


As shown in Fig. 2, restricting the water supplied through watering resulted in progressive soil drying and by the end of the 12 days of water deficit imposition the fresh mass of the soil decreased to approximately $50 \%$ of the value determined at field capacity. Soil drying resulted in the development of a moderate leaf water deficit: when compared to well-watered plants, leaf $\Psi$ decreased by $0.2 \mathrm{MPa}$ during the first 5 days of limited water supply, and at the end of soil drying period $\Psi$ of water-stressed leaves was $0.4 \mathrm{MPa}$ lower than in well-watered ones. Both soil fresh mass and leaf $\Psi$ fully recovered to control levels on the day immediately following rewatering (Fig. 2).

\section{Nitrate reductase activity}

In well-watered plants, foliar activity of the unphosphorylated active form of nitrate reductase $\left(\mathrm{NR}_{\mathrm{act}}\right)$ remained constant throughout the experimental period, being approximately 10-fold higher than values found in the roots of the same plants (Fig. 3). Although the roots of well-watered plants exhibited an apparent tendency for a time-dependent decrease in the activity of nitrate reductase, the observed variation between sampling dates in root $\mathrm{NR}_{\mathrm{act}}$, was not statistically significant (one way Anova, $\mathrm{F}=1.13, \mathrm{P}=0.366$ ).

When soil dried, a strong depression in $\mathrm{NR}_{\mathrm{act}}$ was detected both in roots and leaves (Fig. 3): after 12 days of limited water supply, the activity of nitrate reductase decreased to less than $40 \%$ and $20 \%$ of control values, respectively in roots and leaves. Despite the extent of drought-induced depression in $\mathrm{NR}_{\mathrm{act}}$ being higher in leaves than in roots, soil drying did not eliminate the differences in NR activity between leaves and roots: in plants subjected to more prolonged water deficit $\mathrm{NR}_{\mathrm{act}}$ was still 5-fold higher in leaves than in roots. The degree of recovery in enzyme activity after the relief of water deficit was also dependent on the organ considered: two days following rewatering, no significant differences persisted between 
rewatered and well-watered plants with regard to root $\mathrm{NR}_{\mathrm{act}}$; in contrast, foliar $\mathrm{NR}_{\mathrm{act}}$ only recovered to approximately half the value determined in leaves of control plants.

As shown in Fig. 3, the activation state of NR was about $75 \%$ in leaves of wellwatered plants, irrespective of the sampling date. A lower percentage of the enzyme was unphosphorylated in the roots of the same plants, in which NR activation state increased from $40 \%$ to $60 \%$ throughout the experimental period. In contrast to what occurred at the level of $\mathrm{NR}_{\mathrm{act}}$, soil drying did not negatively affected the activation of nitrate reductase. In fact, values of NR activation state determined in water-stressed plants were slightly, but significantly, higher than those determined in control well-watered plants, both in roots and leaves (Fig. 3).

Rather than being associated with changes in the activation state of the enzyme, the observed variation in $\mathrm{NR}_{\mathrm{act}}$, either resulting from the watering regime or from variability within each treatment, were paralleled by changes in NR activity determined in the absence of magnesium to override post-translational negative regulation of catalytic activity $\left(\mathrm{NR}_{\max }\right)$. As shown in Fig. 4, $\mathrm{NR}_{\mathrm{act}}$ and $\mathrm{NR}_{\max }$ were tightly correlated, both in roots $\left(\mathrm{r}^{2}=0.944, \mathrm{P}<0.001\right)$ and leaves $\left(\mathrm{r}^{2}=0.973, \mathrm{P}<0.001\right)$.

Nitrate concentrations and nitrate flux in the xylem

The observed differences in $\mathrm{NR}_{\mathrm{act}}$ between roots and leaves of well-watered plants (Fig.3) were not associated with different levels of accumulated nitrate, since in the absence of water deficit the concentrations of nitrate in roots and leaves were similar (Fig. 5). Soil drying negatively affected the concentrations of nitrate in roots, leaves (Fig. 5), and xylem sap, as well as the flux of nitrate to the leaves (Fig. 6). Similarly to what occurred with NR activity, the magnitude of drought-induced decline in nitrate was greater in leaves than in roots: at the end of the soil drying period, the concentration of nitrate in the roots of waterstressed plants was about $20 \%$ of that determined in control plants, whereas foliar nitrate content decreased below $10 \%$ of concentrations found in the leaves of well-watered plants, 
even in the case of moderately stressed plants (Fig. 5). As a consequence, in water-stressed plants the levels of nitrate accumulated in tissues was higher in the roots than in the leaves (Fig. 5). The magnitude of drought-induced decline in the xylem sap was similar to that in the roots. As a consequence of water-stressed leaves exhibiting lower transpiration rates than well-watered plants, a slightly more pronounced decline occurred in the flux of nitrate through xylem (Fig. 6).

As shown in Fig. 7, there was a clear relationship between drought-induced changes in the concentration of nitrate and in the inhibition of $\mathrm{NR}_{\max }$ in roots. Effectively, when all the individual data points determined in well-watered and water-stressed plants were considered, nitrate concentration changes accounted for approximately $50 \%$ of maximum NR activity variation in roots $\left(\mathrm{r}^{2}=0.506, \mathrm{P}<0.001\right)$.

At the leaf level, nitrate concentration and $\mathrm{NR}_{\max }$ were also positively correlated $\left(\mathrm{r}^{2}=0.306, \mathrm{P}<0.001\right)$, although not so tightly as in roots. However, observed drought-induced variations in foliar $\mathrm{NR}_{\max }$ were more strongly correlated with the concentration of nitrate in the xylem sap $\left(r^{2}=0.728, P<0.001\right)$, and even more with the flux of nitrate to the leaves (Fig. $\left.7, \mathrm{r}^{2}=0.771, \mathrm{P}<0.001\right)$. A stepwise regression procedure involving concentration of nitrate in roots, concentration of nitrate in the xylem sap and the flux of nitrate to the leaves as predictors in the model, retained the last one as exclusive and sufficient explanatory variable to drought-induced depression in foliar $\mathrm{NR}_{\max }$.

When plants subjected to 12 days of restricted water supply were rehydrated, the concentrations of nitrate in roots (Fig. 5) and xylem (Fig. 6) recovered to control values on the first day following rewatering, the same occurring with the flux of nitrate to the leaves. Because the nitrate flux to the leaves fully recovered when the foliar activity of NR in rewatered plants was still depressed (Fig. 3), a significant build-up of nitrate was detected in 
the leaves of rewatered plants, the concentration of nitrate on those leaves reaching values more than two-fold higher than those found in the leaves of well-watered plants (Fig. 5).

Concentrations of amino acids and soluble sugars

Contrasting with what occurred with $\mathrm{NR}_{\mathrm{act}}$ and nitrate, soil drying did not negatively affect the concentration of amino acids, neither in roots nor in the leaves of the plants subjected to the shortest water deficit period (Fig. 8). However, the concentration of amino acids in the leaves was transiently depressed in the plants subjected to the intermediate stress level, but recovered to control levels as soil drying intensified. Therefore, at the end of the soil drying period no significant differences were detected between well-watered and waterstressed plants as to the concentration of amino acids, both in roots and leaves (Fig. 8). In contrast, as shown in Fig. 9, the concentration of amino acids in the xylem sap of waterstressed plants was halved when compared to values found in control plants. However, drought-induced depression in the concentration of amino acids in the xylem sap was less accentuated than the concomitant decrease in the concentration of nitrate, and therefore the nitrate to amino acids ratio in xylem decreased as a result of soil drying (Fig. 9).

In contrast to nitrate and amino acids, soil drying positively affected the concentration of soluble sugars in the roots, which increased 3-fold compared to well-watered plants. The concentration of soluble sugars also increased at the leaf level, but the extent of droughtinduced sugar accumulation was lower in leaves than in roots (Fig. 8). Both in roots and leaves, the increase in sugar concentration in water-stressed plants resulted mainly from the accumulation of hexose, rather than sucrose. Following rewatering, no significant difference persisted between well-watered and rewatered plants as to the concentration of soluble sugars.

\section{Discussion}

Effects of soil drying on the activity of nitrate reductase 
In accordance with what has been previously reported for leaves of tobacco (FerrarioMéry et al. 1998) and maize (Shaner and Boyer 1976a; Foyer et al. 1998), in the present work, it has been found that soil drying strongly decreased the activity of the unphosphorylated form of nitrate reductase $\left(\mathrm{NR}_{\mathrm{act}}\right)$ in the leaves of sunflower plants (Fig. 3 ). Although drought-induced depression in the activity of the enzyme was less accentuated in roots than in leaves, soil drying also negatively affected $\mathrm{NR}_{\mathrm{act}}$ in the roots of sunflower (Fig. 3). These results are not in accordance with Gollan et al. (1992), who suggested that water deficit promotes nitrate reduction in sunflower roots, on the grounds that soil drying increased the concentration of amino acids in the xylem sap, in contrast to what has been observed in the present work (Fig. 9). In the present work, the inhibitory effect of soil drying on nitrate reduction in the roots was further evidenced by the strong drought-induced depression of NR activity measured under in vitro conditions (Fig. 3), similarly to what has been previously found when wheat roots were dehydrated under osmotic stress (Larsson et al. 1989).

A decrease in the activity of the unphosphorylated active form of nitrate reductase $\left(\mathrm{NR}_{\mathrm{act}}\right)$, as observed in the present work (Fig. 3), may result either from decreased NR protein, and hence total NR activity, or increased inactivation of the existing NR protein. Phosphorylation-dependent inactivation of nitrate reductase has been shown to occur as a result of water deficit in leaves of spinach (Kaiser and Brendle-Behnisch 1991), tomato (Brewitz et al. 1996) and maize (Foyer et al. 1998). However, the negative effects of soil drying on $\mathrm{NR}_{\mathrm{act}}$, which have been detected in the present work, were not associated with increased phosphorylation-dependent inactivation of NR. Instead, as soil dried, the activation state of NR tended to increase rather than decrease, both in roots and leaves: as shown in Fig. 3 , the leaves of plants subjected to the intermediate stress level exhibited the highest value of NR activation state (about 90\%), a value which is close to the upper limit of the range (66- 
88\%) reported for the activation state of foliar NR from well-watered plants of other species (Kandlbinder et al. 2000).

It is well established that sugars and/or sugar phosphates are the main internal signals that regulate the protein kinase(s) and phosphatase that determine the activation state of NR, low sugar levels leading to post-translational inactivation of NR (Kaiser et al. 1999; Kaiser and Huber 2001). In addition, Geiger et al. (1998) reported that the increased activation of $\mathrm{NR}$, observed in leaves of tobacco under enhanced $\mathrm{CO}_{2}$, was correlated with lower accumulation of glutamine and other end-products of nitrogen assimilation. In the present work, soil drying resulted in increased concentrations of sugars, both in roots and leaves of sunflower plants (Fig. 8), similarly to what has been commonly observed in other plants (Quick et al. 1992). Moreover, a transient decrease in the concentration of total amino acids was detected in leaves of plants subjected to the intermediate stress level (Fig. 8), in which the highest value of NR activation state was recorded. Therefore, based on current knowledge on the regulation of the post-translational inactivation of $\mathrm{NR}$, the observed increase in the activation state of NR in sunflower plants is not surprising, being associated with droughtinduced accumulation of sugars, and depression in the concentration of amino acids.

Irrespective of the causes underlying it, drought-induced increase in the activation state of NR was not sufficient to overcome the negative effect of soil drying on $\mathrm{NR}_{\mathrm{act}}$ resulting from changes in the maximum activity of the enzyme determined in the presence of excess EDTA (Fig. 4), which is thought to reflect total NR protein content (Kaiser and Huber 2001). Nitrate reductase has a rather short half-life of several hours. Thus, the existing amount of NR protein depends not only on the rate of synthesis, but also on the rate of degradation that has been reported to increase when excised oat leaves are dehydrated (Kenis et al. 1994). Data from Kaiser and Huber (2001) indicate that sugar signalling may be involved in the control of NR proteolysis and that NR activation always correlates positively with NR protein 
stability. Therefore, since both the concentration of soluble sugars (Fig. 8) and the activation state of NR (Fig. 3) increased in water-stressed sunflower plants, the observed droughtinduced decrease in $\mathrm{NR}_{\max }$ is not likely to result from increased rate of NR degradation, and probably results from inhibition of NR gene transcription, as previously reported for waterstressed leaves of maize (Foyer et al. 1998) and tobacco (Ferrario-Méry et al. 1998).

The negative effects of soil drying on NR activity were paralleled by nitrate depletion both in roots and leaves (Fig. 4). In addition of being the major N-source for plants, nitrate is an important signalling molecule that can directly promote the expression of genes related to nitrate assimilation, namely nitrate reductase (Hoff et al. 1994). This may contribute to explain the relationship between $\mathrm{NR}_{\max }$ and the concentration of nitrate in the roots of sunflower (Fig. 7). At the leaf level, the activity of NR was only loosely correlated with the concentration of nitrate in leaf tissues. This is in accordance with experimental data indicating that the transcription of the NR gene and leaf NR activity require the continuous supply of nitrate through the xylem (Shaner and Boyer 1976b; Kawachi et al. 2002), rather than being regulated by the nitrate content in the whole-leaf which is likely to be strongly dependent on the amounts of nitrate stored within the vacuoles.

The recovery of nitrate reductase activity following rewatering

Under field conditions, plants are subjected to recurrent periods of soil drying and rewatering. Therefore, plant performance under drought conditions is likely to be dependent on their ability to restore physiological processes, including nitrate reduction, following rewatering. In the present work, root NR activity was found to fully recover from the effects of soil drying within the two days which followed rewatering, but the recovery of NR activity in leaves was incomplete within the same period (Fig. 3). A delay in the recovery of nitrate reductase activity in leaves has been previously found by Shaner and Boyer (1976a), when rewatering of maize plants was not accompanied by the increase in nitrate content in xylem 
sap. In the above mentioned study, the authors concluded that resuming nitrate reduction following rewatering was being limited by the delay in the reestablishment of high nitrate flux to the leaves. In the present study, however, the concentration of nitrate in xylem, as well as the nitrate flux to the leaves was similar in rewatered and control plants (Fig. 6). Therefore, the after-effect of drought on foliar NR activity may have resulted from limitations in factors other than the transport of nitrate to the leaves.

Sugars not only regulate the activity of nitrate reductase through modulation of its post-translational inactivation, but may also positively affect the transcription of the NR gene, the nitrate-induced NR expression in leaves being completely overridden when sugars fall below a critical level (Klein et al. 2000). Although water stress often induces an accumulation of soluble sugars, in a previous study we have found that rehydration may be associated with sugar depletion in mature leaves of sunflower (Fonseca et al. 2000). However, in the present study leaf sugar content of rewatered plants did not decrease below values found in control plants (Fig. 8). These results exclude the possibility of the after-effect of drought on foliar NR activity resulting from inhibition of nitrate induction of NR expression due to sugar depletion.

The results from the present study do not allow identifying the causes underlying the observed delay in recovery of foliar NR activity following rewatering, but several hypotheses may be put forward to explain it. According to Hoff et al. (1994), glutamine could be responsible for the negative regulation of the NR transcript level in plant leaves. Although a direct role of glutamine in controlling the expression of NR is open to criticism (Dzuibany et al. 1988), the results of Scheible et al. (2000) suggest that NR expression is inhibited by other down-stream metabolites formed during nitrate assimilation. In another recent work, Müller et al. (2001) reported that malate may also inhibit NR expression, affecting both the NR transcription and NR activity. In the present study we have not quantified malate, and the pool of total amino acids in leaves of rewatered plants was not higher than in leaves of control 
well-watered plants (Fig. 8). However, changes in individual amino acids may not parallel the overall amino acids content (Geiger et al. 1998). Therefore, the possibility that the delay in the recovery of foliar NR activity results from the accumulation of malate or specific amino acids should be investigated.

\section{Conclusions}

In the present work, soil drying significantly depressed the nitrate content and the activity of the active unphosphorylated form of NR, both in roots and leaves of sunflower, the extent of drought effects being greater at the leaf than at the root level. The negative effects of soil drying on NR activity resulted from a strong drought-induced decrease in the maximal activity of NR, rather than from increased post-translational inactivation of NR protein. The decline in $\mathrm{NR}_{\max }$ was linearly correlated with the depletion in nitrate in roots. At the leaf level, the nitrate flux to the leaves through the xylem played a much larger regulatory role than the leaf nitrate content in controlling the activity of nitrate reductase. Two days following rewatering, the activity of NR fully recovered at the root level, but not in leaves. The delay in the recovery of foliar NR activity occurred despite full recovery of nitrate flux to the leaves, and the causes underlying it remain to be identified.

\section{Acknowledgments}

This work was supported by the project POCTI/AGR/36145, which was funded by the Foundation for Science and Technology (FCT, Portugal) and by FEDER (European Union).

\section{References}

Abd-El Baki GK, Siefritz F, Man H-M, Weiner H, Kaldenhoff R, Kaiser WM (2000) Nitrate reductase in Zea mays L. under salinity. Plant, Cell and Environment 23, 515-521.

Borel C, Simonneau T (2002) Is the ABA concentration in the sap collected by pressurizing leaves relevant for analysing drought effects on stomata? Evidence from ABA-fed leaves 
of transgenic plants with modified capacities to synthesize ABA. Journal of Experimental Botany 53, 287-296.

Brewitz E, Larsson C-M, Larsson M (1996) Response of nitrate assimilation and $\mathrm{N}$ translocation in tomato (Lycopersicon esculentum Mill) to reduced ambient air humidity. Journal of Experimental Botany 47, 855-861.

Correia MJ, Pereira JS (1994) Abscisic acid in apoplastic sap can account for the restriction in leaf conductance of white lupins during moderate soil drying and after rewatering. Plant, Cell and Environment 17, 845-852.

Correia MJ, Rodrigues ML, Osório ML, Chaves MM (1999) Effects of growth temperature on the response of lupin stomata to drought and abscisic acid. Australian Journal of Plant Physiology 26, 549-559.

Crawford NM (1995) Nitrate: nutrient and signal for plant growth. The Plant Cell 7, 859-868.

Dzuibany C, Haupt S, Fock H, Biehler K, Migge A, Becker TW (1998) Regulation of nitrate reductase transcript levels by glutamine accumulating in the leaves of a ferredoxindependent glutamate synthase-deficient gluS mutant of Arabidopsis thaliana, and by glutamine provided via the roots. Planta 206, 515-522.

Ferrario-Méry S, Valadier MH, Foyer CH (1998) Overexpression of nitrate reductase in tobacco delays drought-induced decreases in nitrate reductase activity and mRNA. Plant Physiology 117, 293-302.

Fonseca F, David M, Barrote I, Ferreira G, Correia MJ (2000) Interaction between water and nutrient deficiencies in Helianthus annuus. In 'Nitrogen in a sustainable ecosystem. From the cell to the plant'. (Eds MA Martins-Loução and SH Lips) pp. 169-175. (Backhyis Publishers, Leiden, The Netherlands) 
Foyer CH, Valadier MH, Migge A, Becker TH. (1998) Drought-induced effects on nitrate reductase activity and mRNA and on the coordination of nitrogen and carbon metabolism in maize leaves. Plant Physiology 117, 283-292.

Galangau F, Daniel-Vedele F, Moureaux T, Dorbe M-F, Leydecker M-T, Caboche M (1988) Expression of leaf nitrate reductase genes from tomato and tobacco in relation to light-dark regimes and nitrate supply. Plant Physiology 88, 383-388.

Geiger M, Walch-Liu P, Engels C, Harnrcker J, Schulze E-D, Ludewig F, Sonnewald U, Scheible W-R, Stitt M (1998) Enhanced carbon dioxide leads to a modified diurnal rhythm of nitrate reductase activity in older plants, and a large stimulation of nitrate reductase activity and higher levels of amino acids in young tobacco plants. Plant, Cell and Environment 21, 253-268.

Gollan T, Schurr U, Schulze E-D (1992) Stomatal response to drying soil in relation to changes in the xylem sap composition of Helianthus annuus. I. The concentration of cations, anions, aminoacids in, and $\mathrm{pH}$ of, the xylem sap. Plant, Cell and Environment 15, 551-559.

Goupil P, Loncle D, Druart N, Belletre A, Rambour S (1998) Influence of ABA on nitrate reductase activity and carbohydrate metabolism in chicory roots (Chicorium intybus L.). Journal of Experimental Botany 49, 1855-1862.

Hoff T, Truong HN, Caboche M (1994) The use of mutants and transgenic plants to study nitrate assimilation. Plant, Cell and Environment 17, 489-506.

Jones MGK, Outlaw WH, Lowry OH (1977) Enzymic assay of $10^{-7}$ to $10^{-4}$ moles of sucrose in plant tissues. Plant Physiology 60, 379-383.

Kaiser WM, Brendle-Behnisch E (1991) Rapid modulation of spinach leaf nitrate reductase activity by photosynthesis. I. Modulation in vivo by $\mathrm{CO}_{2}$ availability. Plant Physiology 96, 363-367. 
Kaiser WM, Huber SC (2001) Post-translational regulation of nitrate reductase: mechanism, physiological relevance and environmental triggers. Journal of Experimental Botany 52, 1981-1989.

Kaiser WM, Weiner H, Huber SC (1999) Nitrate reductase in higher plants: a case study for transduction of environmental stimuli into control of catalytic activity. Physiologia Plantarum 105, 385-399.

Kandlbinder A, Weiner H, Kaiser WM (2000) Nitrate reductase from leaves of Ricinus (Ricinus communis L.) and spinach (Spinacia oleracea L.) have different regulatory properties. Journal of Experimental Botany 51, 1099-1105.

Kawachi T, Shoji Y, Sugimoto T, Oji Y, Kleinhofs A, Warner RL, Ohtake N, Ohyama T, Sueyoshi K (2002) Role of xylem sap nitrate in the regulation of nitrate reductase gene expression in leaves of barley (Hordeum vulgare L.) seedlings. Soil Science and Plant Nutrition 48, 79-85.

Kenis JD, Rouby MB, Edelman MO, Silvente ST (1994) Inhibition of nitrate reductase by water stress and oxygen in detached oat leaves: a possible mechanism of action. Journal of Plant Physiology 144, 735-739.

Klein D, Morcuende R, Stitt M, Krapp A (2000) Regulation of nitrate reductase expression in leaves by nitrate and nitrogen metabolism is completely overridden when sugars fall below a critical level. Plant, Cell and Environment 23, 863-871.

Larsson M, Larsson C-M, Whitford PN, Clarkson DT (1989) Influence of osmotic stress on nitrate reductase activity in wheat (Triticum aestivum L.) and the role of abscisic acid. Journal of Experimental Botany 40, 1265-1271.

Long DM, Oaks A (1990) Stabilization of nitrate reductase in maize roots by chymostatin. Plant Physiology 93, 846-850. 
MacKintosh C, Douglas P, Lillo C (1995) Identification of a protein that inhibits the phosphorylated form of nitrate reductase from spinach (Spinacia olearacea) leaves. Plant Physiology 107, 451-457.

Magné C, Larher F (1992) High sugar content of extracts interferes with colorimetric determination of aminoacids and free proline. Analytical Biochemistry 200, 115-118.

Müller C, Scheible W-R, Stitt M, Krapp A (2001) Influence of malate and 2-oxoglutarate on the NIA transcript level and nitrate reductase activity in tobacco leaves. Plant, Cell and Environment 24, 191-203.

Pajuelo P, Pajuelo E, Orea A, Romero JM, Márquez AJ (2002) Influence of plant age and growth conditions on nitrate assimilation in roots of Lotus japonicus plants. Functional Plant Biology 29, 485-494.

Quick WP, Chaves MM, Wendler R, David MM, Rodrigues ML, Passarinho JA, Pereira JS, Adcock MD, Leegood RC, Stitt M (1992) The effect of water stress on photosynthetic carbon metabolism in four species grown under field conditions. Plant, Cell and Environment 15, 25-35.

Scheible WR, Krapp A, Stitt M (2000) Reciprocal diurnal changes of phosphoenolpyruvate carboxylase expression and cytosolic pyruvate kinase, citrate synthase and NADPisocitrate dehydrogenase expression regulate organic acid metabolism during nitrate assimilation in tobacco leaves. Plant, Cell and Environment 23, 1155-1167.

Scheurwater I, Koren M, Lambers H, Atkin OK (2002) The contribution of roots and shoots to whole plant nitrate reduction in fast- and slow-growing grass species. Journal of Experimental Botany 53, 1635-1642.

Schurr U (1998) Xylem sap sampling - new approaches to an old topic. Trends in Plant Science 3, 293-298. 
Shaner DL, Boyer JS (1976a) Nitrate reductase activity in maize (Zea mays L.) leaves. II. Regulation by nitrate flux at low leaf water potential. Plant Physiology 58, 505-509.

Shaner DL, Boyer JS (1976b) Nitrate reductase activity in maize (Zea mays L.) leaves. I. Regulation by nitrate flux. Plant Physiology 58, 499-504.

Stitt M, Müller C, Matt P, Gibon Y, Carillo P, Morcuende R, Scheible W-R, Krapp A (2002) Steps towards an integrated view of nitrogen metabolism. Journal of Experimental Botany 53, 959-970.

Stöhr C, Mäck G (2001) Diurnal changes in nitrogen assimilation of tobacco roots. Journal of Experimental Botany 52, 1283-1289. 
Fig. 1. Nitrate concentrations determined in the feeding solutions and in the xylem exudates collected from detached shoots. Values shown are mean \pm standard error of at least four replicates. Dotted line represents the 1:1 line.

Fig. 2. Soil fresh mass and leaf water potential $(\Psi)$ of well-watered (closed circles) and water-stressed (open circles) sunflower plants. Values shown are mean \pm standard error of at least four replicates. Means from waterstress treatment that are significantly different from the well-watered controls are marked with $*(\mathrm{P}<0.05)$, ** $(\mathrm{P}<0.01)$ or $* * *(\mathrm{P}<0.001)$.

Fig. 3. Activity of the active NR unphosphorylated form determined in the presence of $\mathrm{Mg}^{2+}\left(\mathrm{NR}_{\mathrm{act}}\right)$ and $\mathrm{NR}$ activation state determined in leaves (left panel) and roots (right panel) of well-watered (closed circles) and water-stressed (open circles) sunflower plants. Values shown are mean \pm standard error of at least four replicates. Means from water-stress treatment that are significantly different from the well-watered controls are marked with $*(\mathrm{P}<0.05), * *(\mathrm{P}<0.01)$ or $* * *(\mathrm{P}<0.001)$.

Fig. 4. Relationships between the activity of the NR unphosphorylated form determined in the presence of $\mathrm{Mg}^{2+}$ $\left(\mathrm{NR}_{\mathrm{act}}\right)$ and maximum $\mathrm{NR}$ activity determined in the presence of excess EDTA $\left(\mathrm{NR}_{\max }\right)$. Values shown are individual data points and the respective regression lines, determined in roots (open circles, $\mathrm{Y}=0.061+0.379$ $\mathrm{X}$ ) and leaves (closed circles, $\mathrm{Y}=0.223+0.719 \mathrm{X}$ ) of well-watered, water-stressed and rewatered sunflower plants.

Fig. 5. Nitrate concentrations determined in leaves (left panel) and roots (right panel) of well-watered (closed circles) and water-stressed (open circles) sunflower plants. Values shown are mean \pm standard error of at least four replicates. Means from water-stress treatment that are significantly different from the well-watered controls are marked with * $(\mathrm{P}<0.05), * *(\mathrm{P}<0.01)$ or $* * *(\mathrm{P}<0.001)$.

Fig. 6. Concentration of nitrate in the xylem sap (top panel), transpiration rate (middle panel) and the flux of nitrate through the xylem (bottom panel) determined in well-watered (closed circles) and water-stressed (open circles) sunflower plants. Values shown are mean \pm standard error of at least four replicates. Means from waterstress treatment that are significantly different from the well-watered controls are marked with $*(\mathrm{P}<0.05)$, ** $(\mathrm{P}<0.01)$ or $* * *(\mathrm{P}<0.001)$.

Fig. 7. Relationship between the maximum $\mathrm{NR}$ activity $\left(\mathrm{NR}_{\max }\right)$ and the concentrations of nitrate in roots (right panel), and relationship between $\mathrm{NR}_{\max }$ in leaves and the flux of nitrate through the xylem (left panel). Values 
shown are individual data points, and the respective regression lines determined in leaves $(\mathrm{Y}=0.299+7.989 \mathrm{X})$ and roots ( $\mathrm{Y}=0.265+0.026 \mathrm{X})$ of well-watered (closed symbols) and water-stressed (open symbols) plants.

Fig. 8. Concentrations of amino acids (top panels) and soluble sugars (bottom panels) determined in leaves (left panels) and roots (right panels) of well-watered (closed circles) and water-stressed (open circles) sunflower plants. Values shown are mean \pm standard error of at least four replicates. Means from water-stress treatment that are significantly different from the well-watered controls are marked with $*(\mathrm{P}<0.05),{ }^{* *}(\mathrm{P}<0.01)$ or $* * *$ $(\mathrm{P}<0.001)$.

Fig. 9. Concentration of amino acids (top panel) and nitrate to amino acids ratio (bottom panel) determined in the xylem sap of well-watered (closed circles) and water-stressed (open circles) sunflower plants. Values shown are mean \pm standard error of at least four replicates. Means from water-stress treatment that are significantly different from the well-watered controls are marked with * $(\mathrm{P}<0.05),{ }^{* *}(\mathrm{P}<0.01)$ or $* * *(\mathrm{P}<0.001)$. 
Fig. 1

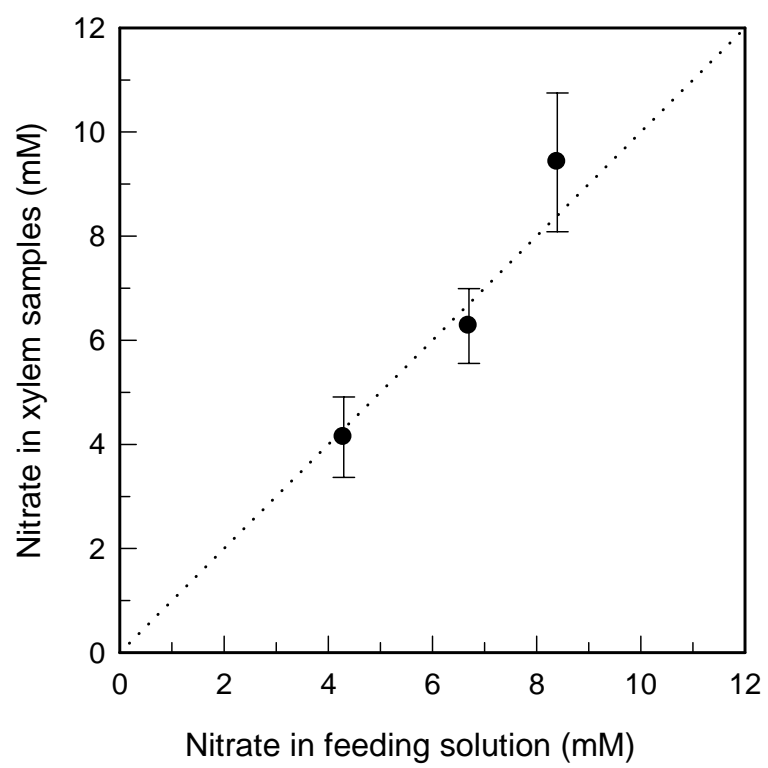

Fig. 2

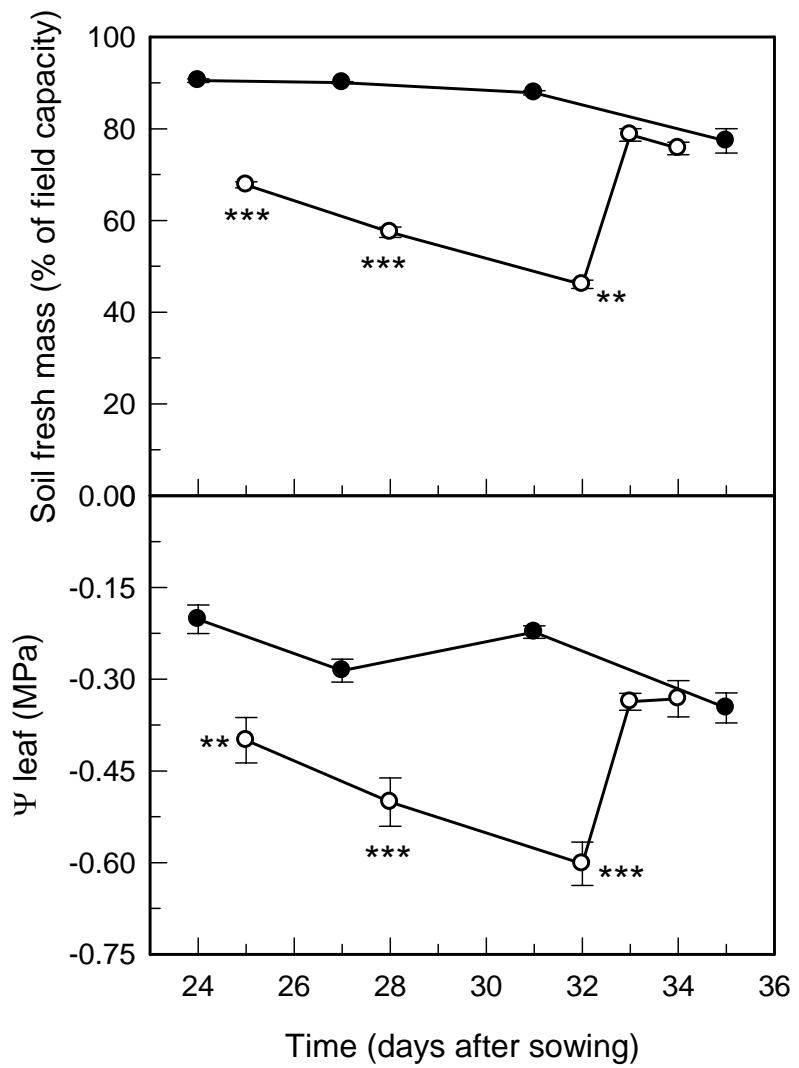


Fig. 3

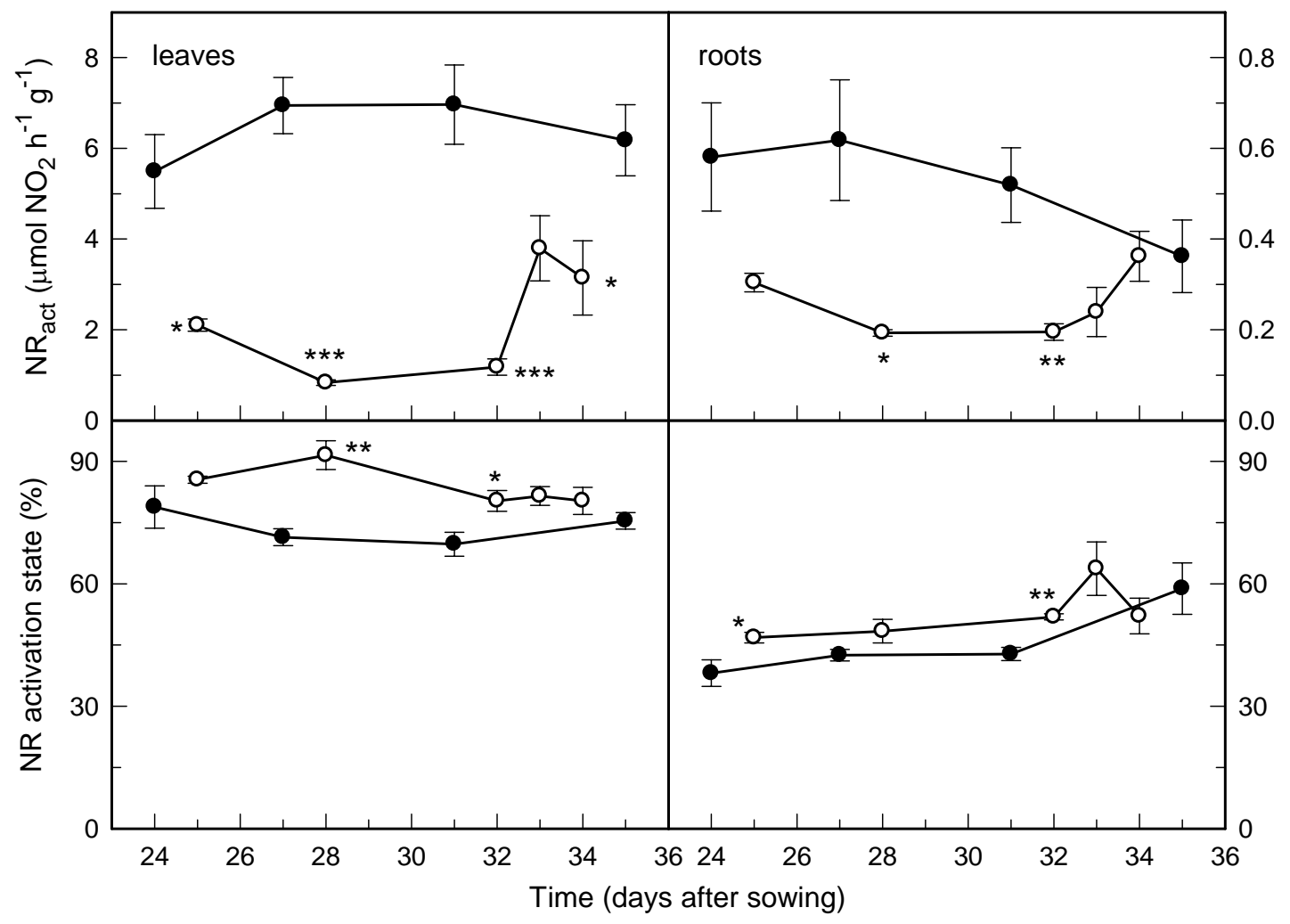

Fig. 4

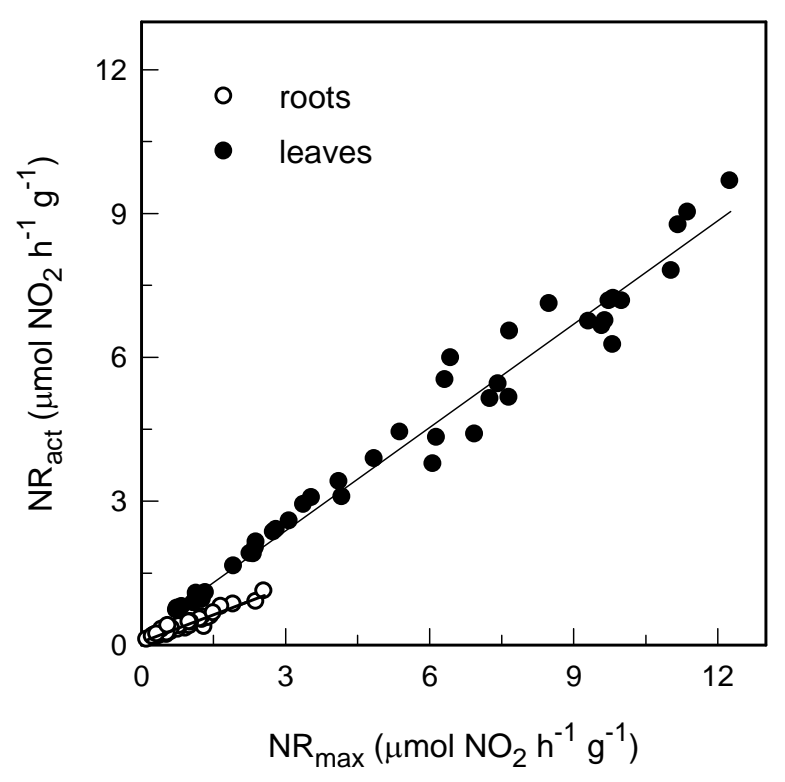


Fig. 5

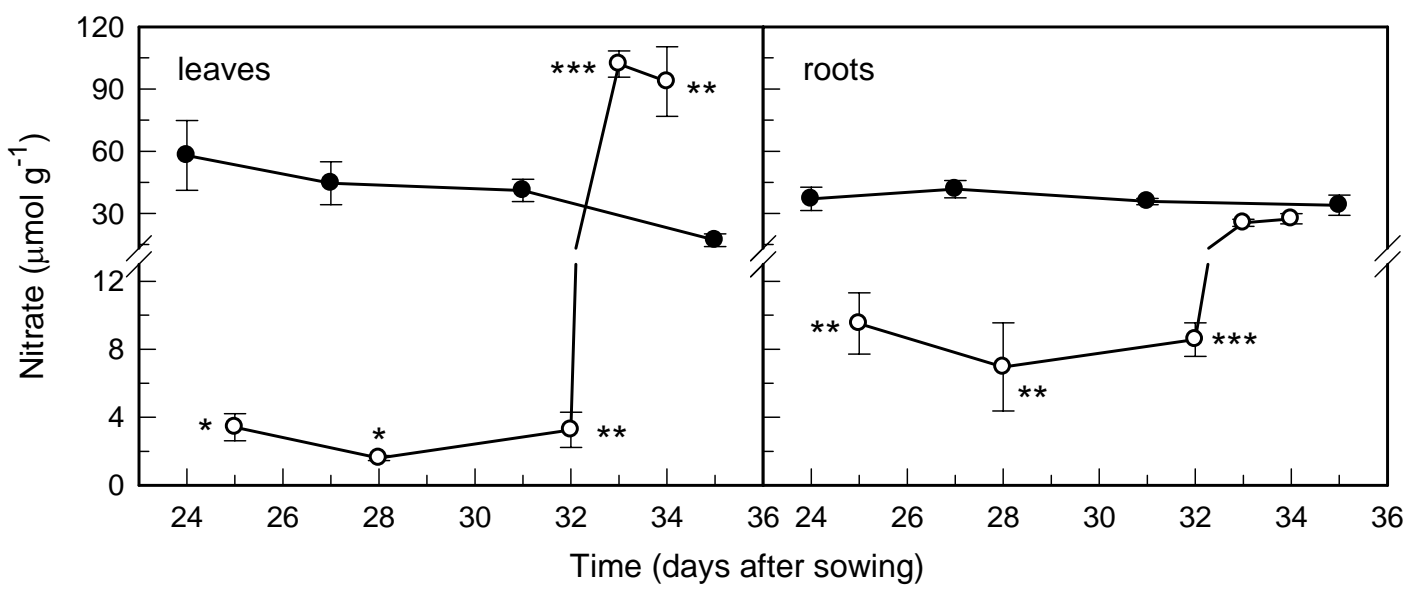

Fig. 6

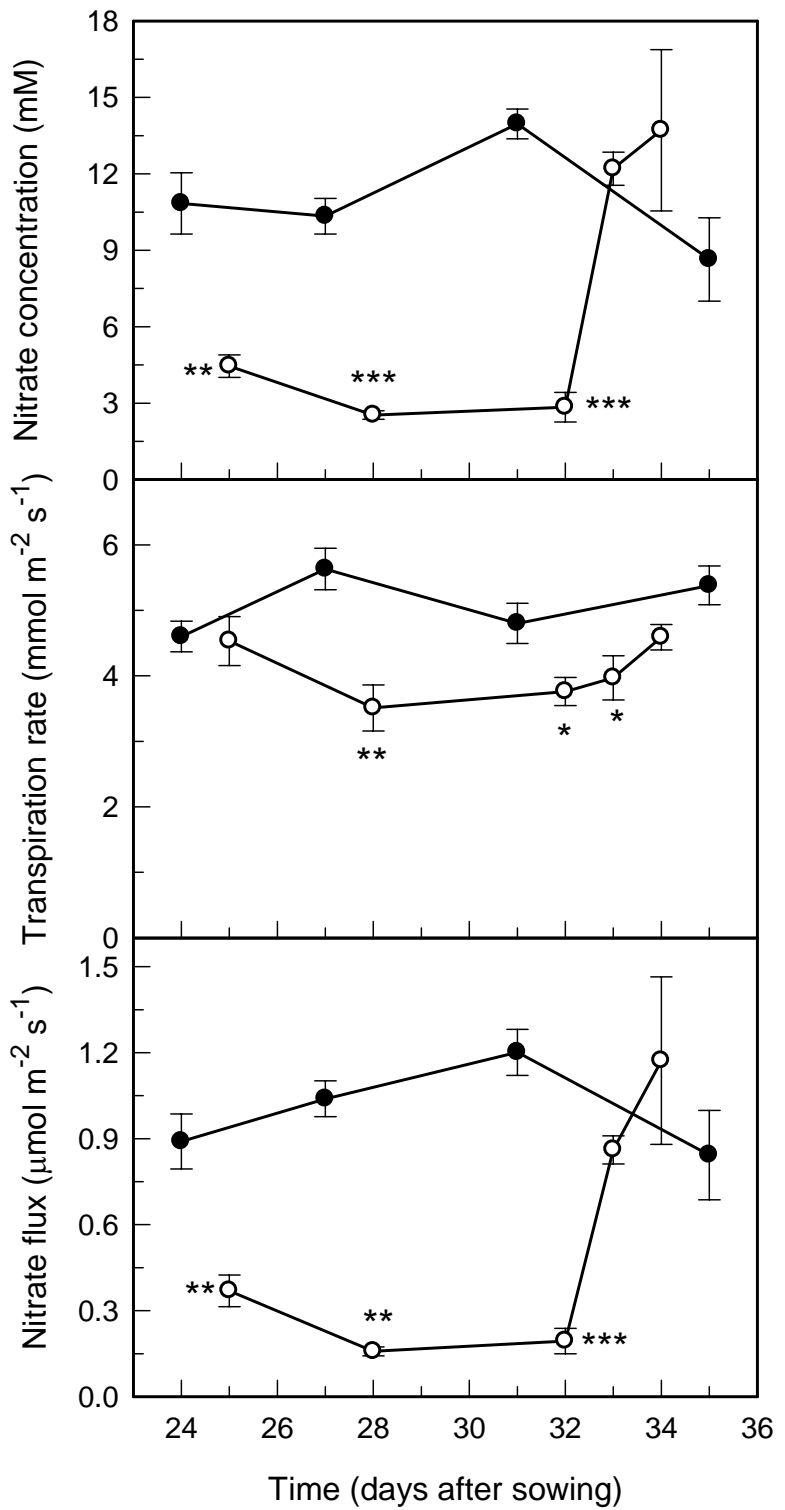


Fig. 7

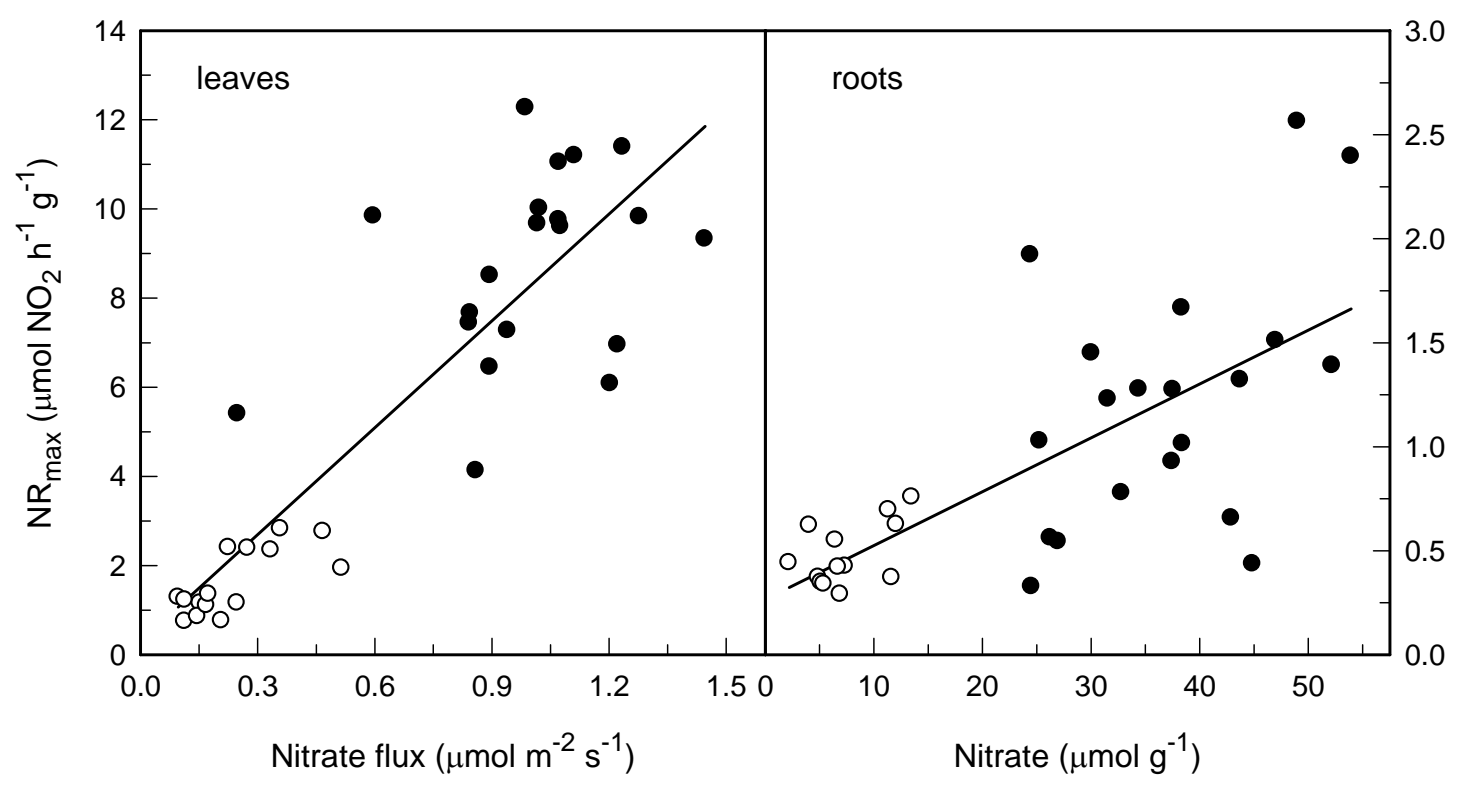

Fig. 8

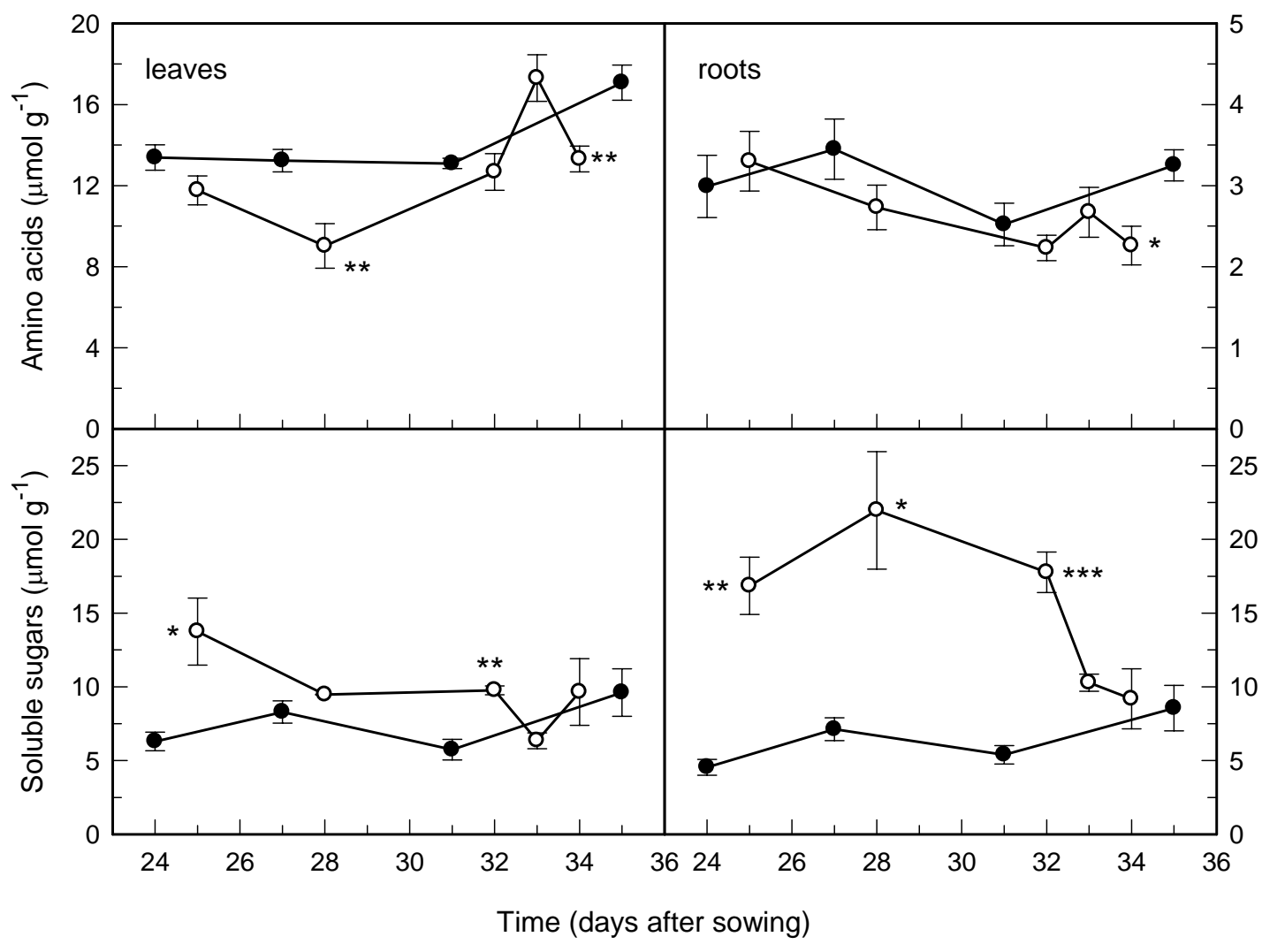


Fig. 9

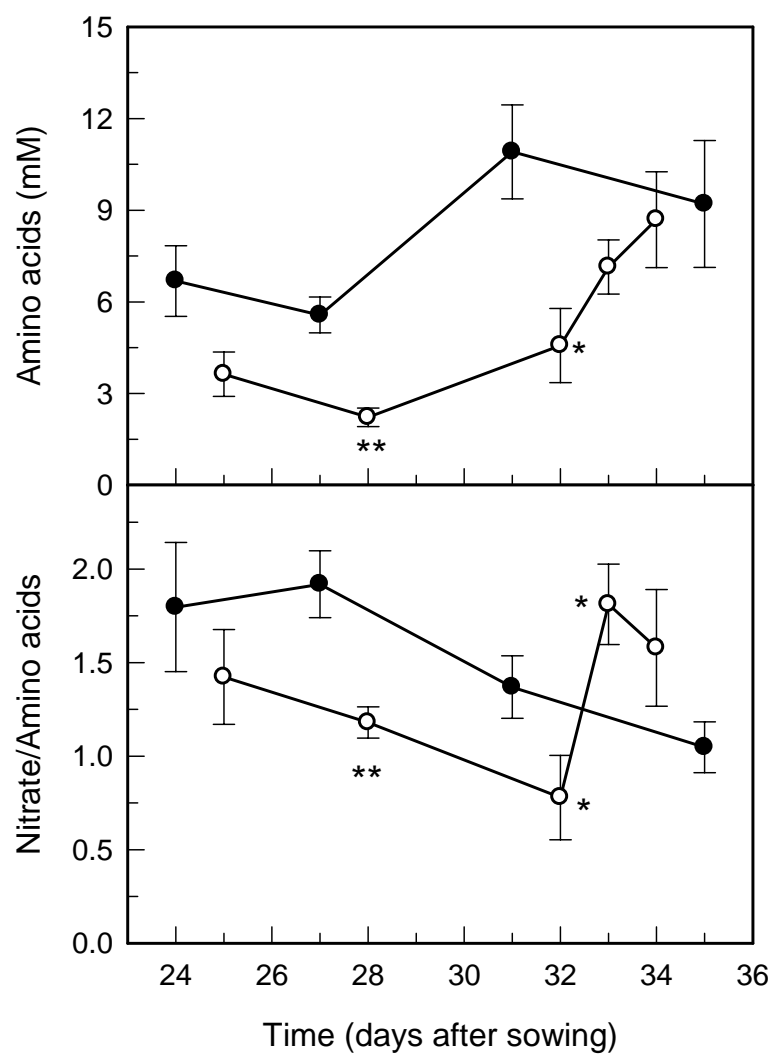

